\title{
First Record of the Little-known Genus Hellwigia (Hymenoptera: Ichneumonidae: Campopleginae) from Korea
}

\author{
Jin-Kyung Choi ${ }^{1}$, Jong-Chul Jeong ${ }^{2}$, Jong-Wook Lee ${ }^{3, *}$ \\ ${ }^{1}$ National Institute of Environmental Research, Incheon 404-708, Korea \\ ${ }^{2}$ National Park Research Institute, Korea National Park Service, Namwon 590-811, Korea \\ ${ }^{3}$ Department of Life Sciences, Yeungnam University, Gyeongsan 712-749, Korea
}

\begin{abstract}
We report on the discovery of Hellwigia obscura Gravenhorst, 1823, a species new to Korea. A description based on both sexes with photographs and a key to the world Hellwigia species are provided.
\end{abstract}

Keywords: Campopleginae, Hellwigia obscura, Ichneumonidae, Korea

\section{INTRODUCTION}

The genus Hellwigia is rare in collections of the Campopleginae and was firstly described by Gravenhorst in 1823 based on Hellwigia elegans. The world fauna of Hellwigia is comprised of only three described species (Yu et al., 2005), one of which was recorded as a fossil.

This small genus has been included as a member of the tribe Hellwigiini within the Campopleginae (Ashmead, 1900; Schmiedeknecht, 1914; Ceballos, 1925; Meyer, 1926; Townes et al., 1965; Townes, 1970; Kasparyan, 1981). But, Kirchner (1867) and Szépligeti (1905a) recognized this genus as a member of the subfamily Ophiononae. On the other hand, Gaulle (1908) insisted that it belongs to the tribe Anomalonini and Enderlein (1912) placed it in the tribe Gravenhorstiini of the Anomaloninae. This genus is currently recognized as the independent subfamily Campopleginae (Wahl, 1991, 1999; Yu and Horstmann, 1997; Belshaw and Quicke, 2002). However, Quicke et al. (2005) suggested that this subfamily designation is inappropriate, based on morphological, molecular, and simultaneous analyses. Recognizing the variety of opinions concerning the systematic position of the genus Hellwigia, we have presently recorded this genus as a member of the subfamily Campopleginae.

The biology of the Hellwigia is unclear. This genus is distributed in Eastern Palaearctic, Nearctic and Western Palae- arctic regions (Yu et al., 2005). Also, the fossil was recovered from the Florissant shales (Miocene) of Colorado (Nearctic) (Brues, 1910).

The two extant species of the genus Hellwigia are very similar and both can be recognized easily by the strongly notched eye opposite the antennal sockets (Figs. 1D, 2B, 3B) in combination with the venation of the 2 nd intercubitus of wings, with the fore wing being strongly bent (Figs. 1L, 2K, $3 \mathrm{~L}$ ). The discovery of $H$. obscura as reported in the present study is the first record of Hellwigia from Korea.

Materials were collected by sweeping. They have been deposited in the animal systematic laboratory of Yeungnam University (YNUE), Gyeongsan, Korea. Some specimens examined in this study are acquired on loan from the Zoologisches Museum, Invalidenstrasse (ZMHU), Berlin, Germany. Specimens were examined by stereo microscope (Zeiss Stemi SV 11 Apo; Carl Zeiss, Göttingen, Germany) and key characters shown in photographs were produced with a Delta imaging system (i-Delta 2.6; iMTechnology, Daejeon, Korea).

Abbreviations are as follows. TD, type depository; TS, type species; HINZ, Zoologisches Staatssammlung, Münchhausenstrasse 21, D-81247 München, Germany (R. Hinz collection); IZU, Instytut Zoologiczny Universytetu, Sienkiewicza 21, Wroclaw, Poland (Gravenhorst collection); TMA, Termeszettudomanyi Muzeum Allattara, Barossa-Utea 13, Budapest H-1088, Hungary; GG, Gyeonggi-do. (c) This is an Open Access article distributed under the terms of the Creative Commons Attribution Non-Commercial License (http://creativecommons.org/ licenses/by-nc/3.0/) which permits unrestricted non-commercial use, distribution, and reproduction in any medium, provided the original work is properly cited.
*To whom correspondence should be addressed

Tel: 82-53-810-2376, Fax: 82-53-811-2376

E-mail: jwlee1@ynu.ac.kr 


\section{SYSTEMATIC ACCOUNTS}

Order Hymenoptera

Family Ichneumonidae Latreille, 1802

$1 *$ Genus Hellwigia Gravenhorst, 1823

Hellwigia Gravenhorst, 1823: 318. TS: Hellwigia elegans Gravenhorst.

Diamon Gistel, 1848: 216.

Protohellwigia Brues, 1910: 66. TS: Protohellwigia obsoleta Brues, by monotypy.

Heinrichiella Hedwig, 1949: 54. TS: Heinrichiella monstrosa Hedwig.

Diagnosis. Hellwigia can be distinguished from all other Ichneumonidae by combination of the following characters: head not impressed behind ocelli; eye strongly notched opposite antennal sockets; fore wing without areolet, the intercubitus strongly curved and opposite or distad of 2 nd recurrent vein.
Key to the extant species of genus Hellwigia Gravenhorst in the world

1. Apical part of antenna strongly swollen (Figs. 1M, 2A); temple weakly convex (Figs. 1G, 2E); metasoma reddish brown, basal part of each tergites black (Fig. 2A)

H. elegans

- Antenna normal, not strongly swollen at apically (Fig. 3M); temple flat (Fig. 3F); metasoma black, 3-4 tergites reddish brown (Fig. 3A)

H. obscura

Hellwigia elegans Gravenhorst, 1823 (Figs. 1, 2)

Hellwigia elegans Gravenhorst, 1823: 315. Lectotype: female; TD: IZU.

Materials examined. [Voucher] 1우, Deutschland, \#11402; $1 \sigma^{7}$, Deutschland, Pohlarien, Gerstaecker; 1 우, Schmiedeknecht.

Description (female). Color: Head black; scape and pedicel

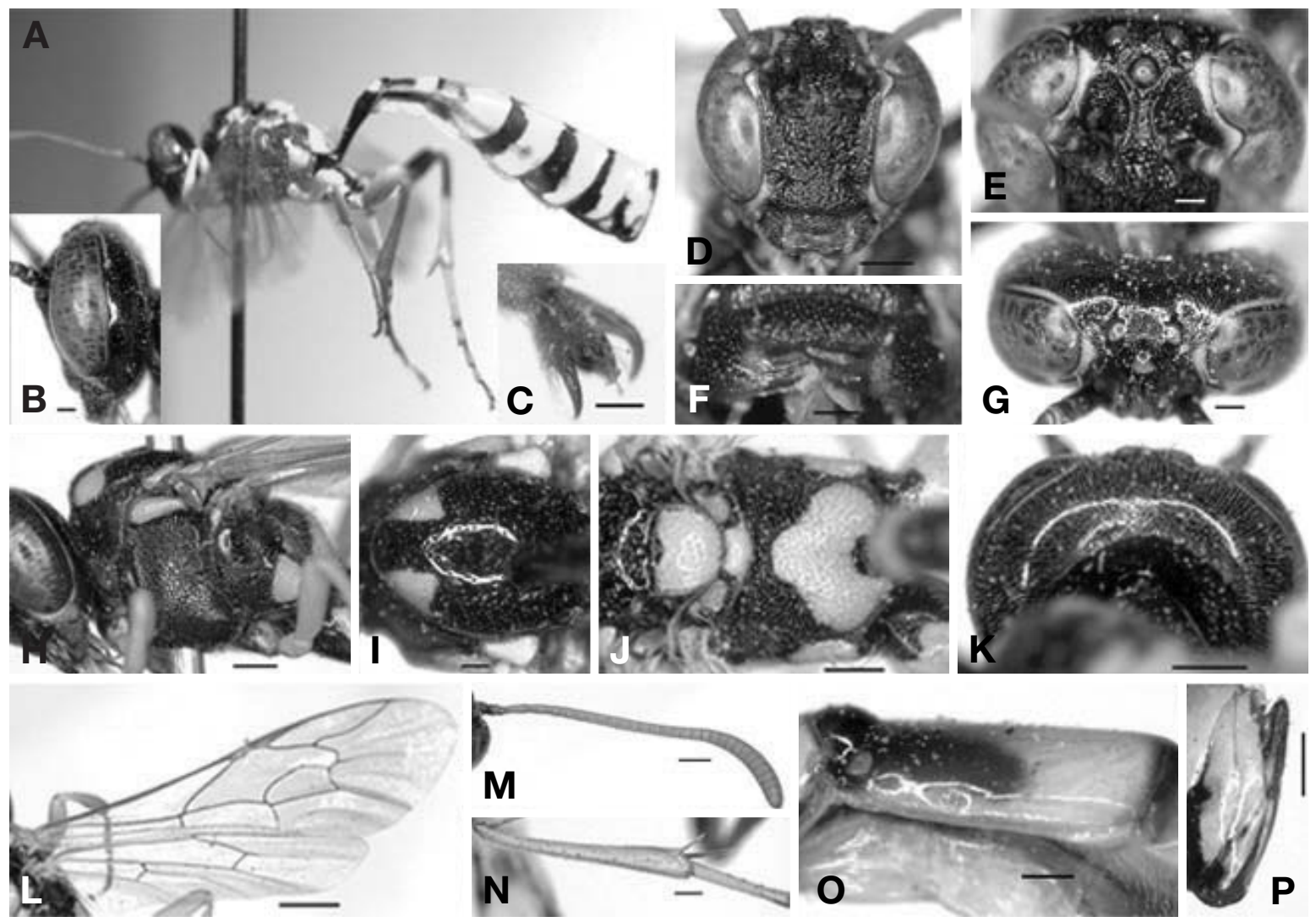

Fig. 1. Hellwigia elegans Gravenhorst, 1823 (female). A, Habitus in lateral; B, Head in lateral; C, Tarsal claw; D, Head in frontal; E, Frons; F, Mandible; G, Head in dorsal; H, Mesopleurum; I, Mesonotum; J, Scutellum and propodeum; K, Occipital carina; L, Wings; M, Antenna; N, Hind tibia; O, Thyridium; P, Ovipositor. Scale bars: B, E-G, I, N, O=0.2 mm; C=0.1 mm; D, H, J, K, M, P=0.5 mm; $\mathrm{L}=1 \mathrm{~mm}$.

Korean name: ${ }^{*}$ 거짓왕자루맵시벌속(신칭) 


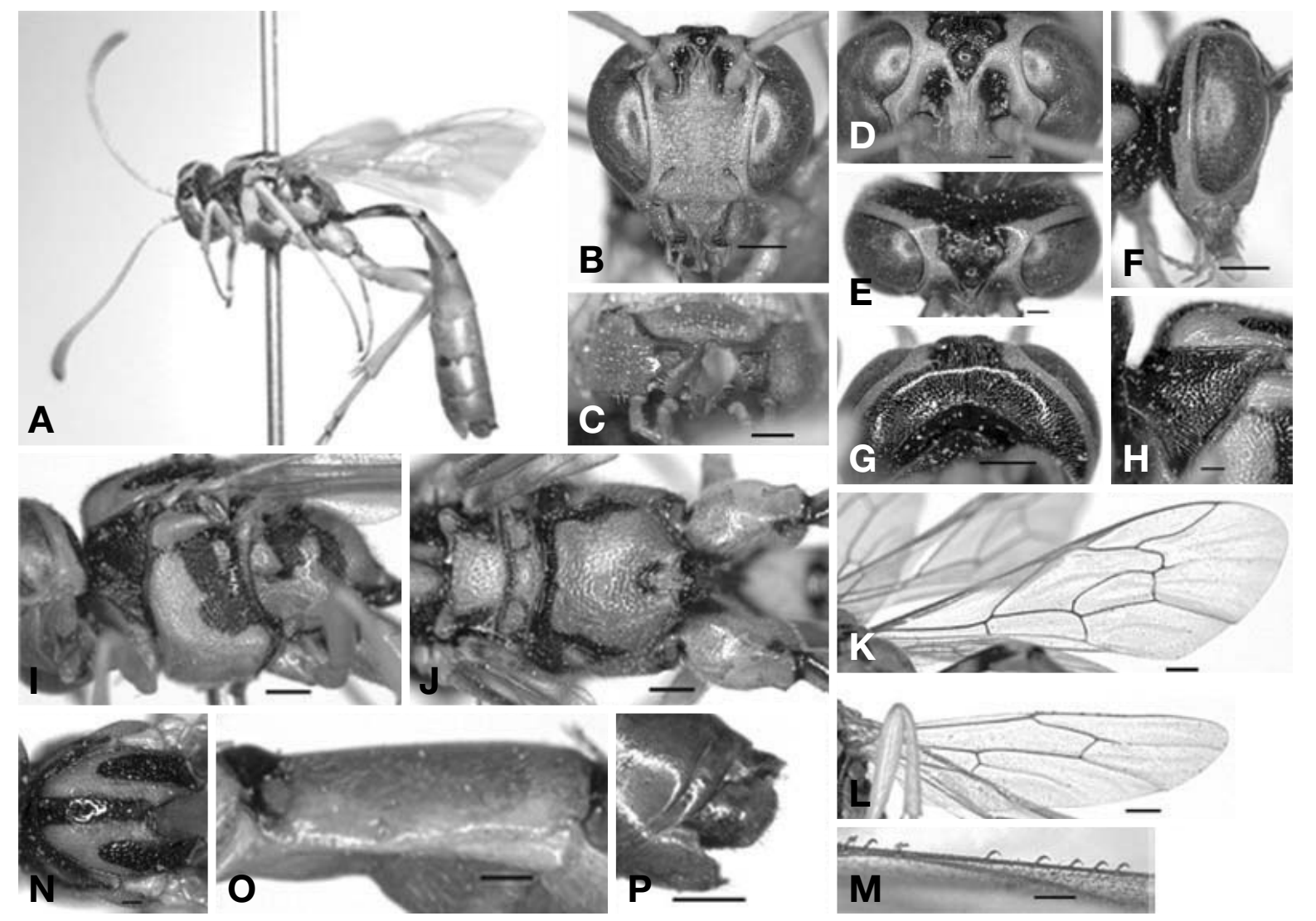

Fig. 2. Hellwigia elegans Gravenhorst, 1823 (male). A, Habitus in lateral; $B$, Head in frontal; C, Mandible; $D$, Frons; $E$, Head in dorsal; F, Head in lateral; G, Occipital carina; H, Pronotum; I, Mesopleurum; J, Scutellum and propodeum; K, Fore wing; $L$, Hind wing; $M$, Distal hamuli of hind wing; N, Mesonotum; O, Thyridium; P, Clasper of male. Scale bars: B, F, G, I, K, L, P=0.5 mm; C-E, H, J, M$\mathrm{O}=0.2 \mathrm{~mm}$.

blackish brown, antenna yellowish brown, clypeus black, labrum dark blackish brown; mandible black basally, brown apically; malar space yellow, upper orbit of eyes narrowly yellow; labial palp and maxillary palp yellow; mesosoma black, upper part of prepectus with yellow spot; tegula and lower part of tegula yellow; mesonotum black with two yellow spot anterolaterally (Fig. 1I); scutellum and postscutellum yellow in dorsal view; propodeum mostly yellow except anterolaterally (Fig. 1J); fore leg yellow, except coxa black; mid leg yellow, except coxa black ventrally; hind coxa black ventrally, with yellow spot dorsally, trochanter yellow, with black spot dorsally, trochantellus yellow, femur yellow, inner part of femur with brown spot, tibia and tarsus yellow; petiole black except apical yellow, metasoma yellow, with black band basally; ovipositor sheath yellow and apical part black.

Head: Face rugosely, roughly punctuate (Fig. 1D); frons with weakly two vertical ridges (Fig. 1E); vertex closely finely punctate; occiput flat and polished, occipital carina complete (Fig. 1K); temple weakly convex, finely slightly punctate, with short hair; clypeus weakly convex, broad and truncated, not separated from face (Fig. 1D); mandibles long, stout and sharp, broad basally and curved; upper tooth longer than lower (Fig. 1F); labial palp with 4 segments and maxillary palp with 5 segments; inner margins of eyes weakly convergent ventrally; antenna socket opposite to inner margin of eyes very strong dent; ocelli small; antenna very strongly swollen at apically (Fig. 1M), antenna with 29 flagellomeres.

Mesosoma: Pronotum with loose punctures, upper part convex, upper part flat and lower part rugosely reticulated and impressed; mesonotum convex, loosely irregulatly punctuate, notauli absent (Fig. 1I); upper part of mesopleuron convex, loosely punctuate, mesopleural suture with indentations; speculum cancave and with transverse stripe, mesopleural pit absent; prepectal carina, epicnemial carina, and postpectal carina present; sternaulus absent; scutellum loosely slightly punctate; lateral carina strongly complete; postscutellum broader than high (Fig. 1J); metapleuron closely punctuate, with very strong pit; propodeum loosely punctuate, rugosely punctuate, propodeal spiracle large, long crescent shape, connected to pleural suture; propodeum carina 
absent (Fig. 1J); legs slender; all tibia broad with short spine (Fig. 1N), hind tarsi with spine ventrally; hind tarsal claw simple and strongly curved (Fig. 1C); basal vein of fore wing distad to nervulus, postnervulus with one bulla; 1st recurrent vein and 2nd recurrent vein with one bulla, 1st intercubitus absent; hind wing nervellus intercepted medially, discoidella present (Fig. 1L), hind wing with discontinuous 8 distal hamuli.

Metasoma: Slender; petiole without lateral carina, glymma absent, polished; spiracle located to middle behind of petiole; thyridium circle and impressed; separated from base of 2 nd tergite by about less than half of its diameter (Fig. 10 ); ovipositor short, ovipositor sheath as long as tergite deep (Fig. 1P).

Male (similar to female except for the following). Color: Head reddish brown; scape and pedicel yellow (Fig. 2B), impressed area of antenna sockets black, ocelli area black; antenna yellow; vertex and temple black; surrounded margin of eyes reddish brown; clypeus reddish brown; labrum brown; mandible reddish brown, apical part dark brown; labial palp and maxillary palp yellowish brown; mesosoma reddish brown, pronotum black (Fig. $2 \mathrm{H}$ ), tegula yellow; mesonotum reddish brown three black line (Fig. 2N); mesopleurum yellow, with black spot; speculum yellow; scutellum and postscutellum yellow in dorsal view; propodeum reddish brown, basal part black, area of pleural carina black (Fig. 2J); fore leg and mid leg yellow; hind leg yellow to reddish brown, hind trochanter with black line dorsally; petiole black, postpetiole yellow; metasoma reddish brown; clasper of male brown.

Head: Ocelli area very convex; mandible short and blunt, upper tooth as long as lower (Fig. 2C); antenna with 30 flagellomeres.

Mesosoma: Lower part of pronotum with transverse stripe, impressed; speculum convex and with transverse stripe; pleural carina of propodeum present.

Metasoma: Clasper of male broad and short (Fig. 2P).

Distribution. Austria, Bulgaria, Czechoslovakia, France, Germany, Hungary, Iran, Israel, Kazakhstan, Norway, Poland, Romania, Russia, Spain, Sweden, Ukraine.

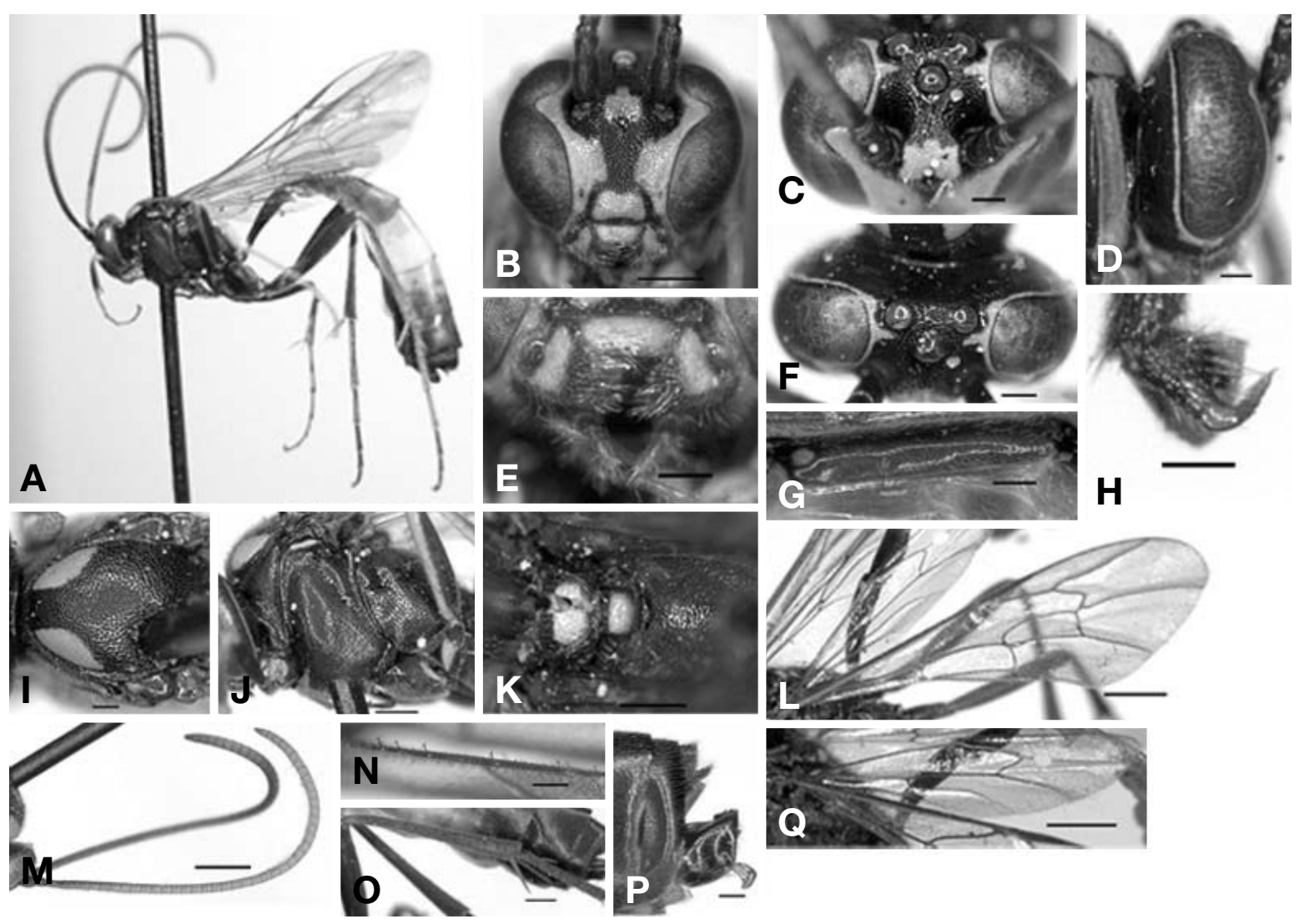

Fig. 3. Hellwigia obscura Gravenhorst, 1823 (male). $A$, Habitus in lateral; $B$, Head in frontal; $C$, Frons; $D$, Head in lateral; $E$, Mandible; F, Head in dorsal; G, Thyridium; H, Tarsal claw; I, Mesonotum; J, Mesopleurum; K, Scutellum; L, Fore wing; M, Antenna; N, Distal hamuli of hind wing; $\mathrm{O}$, Hind tibia; $\mathrm{P}$, Clasper and adeagus of male; $\mathrm{Q}$, Hind wing. Scale bars: $\mathrm{B}, \mathrm{J}, \mathrm{K}, \mathrm{O}=0.5 \mathrm{~mm}$; $\mathrm{C}-\mathrm{G}, \mathrm{I}, \mathrm{N}, \mathrm{P}=0.2$ $\mathrm{mm} ; \mathrm{H}=0.1 \mathrm{~mm} ; \mathrm{L}, \mathrm{M}, \mathrm{Q}=1 \mathrm{~mm}$. 
${ }^{1 *}$ Hellwigia obscura Gravenhorst, 1823 (Fig. 3)

Hellwigia obscura Gravenhorst, 1823: 315. Type: female; TD: IZU.

Hellwigia intermedia Szépligeti, 1905b: 508. Type: male; TD: TMA.

Heinrichiella monstrosa Hedwig, 1949: 54. Type: female; TD: HINZ.

Materials examined. Korea: $1 \oslash^{\nearrow}$, GG, Yongmunsan, 1 Sep 1980, Jang KS; [Voucher] Germany: 1 『, Berghausen, 4 Sep 1927, Hohndorf; $2 \sigma^{\nearrow}$, Schmiedeknecht.

Description (male). Color: Head yellow, face black spot medially; scape and pedicel dark brown, antenna yellowish brown; vertex and temple black; internal space of antenna sockets black, middle area of antenna sockets yellow; surrounded margin of eyes yellow; clypeus yellow, surrounded margin of clypeus black; labrum yellow; mandible yellow basally, dark brown medially, labial palp and maxillary palp yellowish brown; mesosoma black, upper part of prepectus with yellow spot; tegula black and lower part of tegula yellow; mesonotum black with two yellow spot basally; scutellum and postscutellum yellow in dorsal view; fore coxa yellow dorsally, black ventrally, trochanter yellow, trochantellus brown, femur yellow dorsally, dark brown ventrally, tibia and tarsi brown; mid coxa to femur black ventrally, yellow dorsally, tibia and tarsi yellow; hind coax to femur black, tibia and tarsi dark brown; petiole and 2nd tergite black, with yellow spot apical-dorsally, thyridium yellow; 3-4 tergites reddish brown, 5-8 tergites black; clasper of male black.

Head: Face loosely, finely punctate; frons with two vertical ridges; vertex rugosely punctate; occiput flat and polished, occipital carina complete; temple flat, finely slightly punctate, with short hair; clypeus convex and truncated, separated from face by black line (Fig. 3B); mandibles short and stout, broad basally; upper tooth longer than lower (Fig. 3E), with long hairs; labial palp with 3 segments and maxillary palp with 4 segments; inner margins of eyes weakly convergent ventrally; antenna socket opposite to inner margin of eyes very strong dent; ocelli small; antenna normal, not strongly swollen at apically (Fig. 3M), antenna with 46 flagellomeres.

Mesosoma: Pronotum with loosely strong punctures, upper part convex, lower part reticulated and impressed; mesonotum convex, loosely finely punctuate, notauli absent (Fig. 3I); upper part of mesopleuron convex, loosely finely punctuate, mesopleural suture with indentations; speculum flat and subpolished, mesopleural pit weakly present; prepectal carina, epicnemial carina, and postpectal carina present; sternaulus absent; scutellum slightly punctate; lateral carina strongly complete; postscutellum broader than high; metapleuron very loosely punctuate, with very strong pit; propodeum loosely punctuate basally, rugosely punctuate apically, propodeal spiracle large, long oval, connected to pleural suture; propodeum carina absent; legs slender; all tibia with short spine (Fig. 3O), hind tarsi with spine; hind tarsal claw simple and strongly curved (Fig. 3H); basal vein of fore wing distad to nervulus, postnervulus with one bulla; 1 st recurrent vein and 2 nd recurrent vein with one bulla, 1 st intercubitus absent (Fig. 3L); hind wing nervellus intercepted medially, discoidella present (Fig. 3Q), hind wing with discontinuous 6 distal hamuli.

Metasoma: Slender; petiole without lateral carina, glymma absent, spiracle located to middle behind of petiole; thyridium circle and impressed (Fig. 3G); separated from base of 2nd tergite by about half of its diameter.

Distribution. Korea (new record), Austria, Belgium, Bulgaria, Croatia, France, Germany, Hungary, Italy, Mongolia, Romania, Yugoslavia.

\section{ACKNOWLEDGEMENTS}

We thank Dr. Frank Koch of the Zoologisches Museum Invalidenstrasse Berlin Germany, for providing voucher specimens used in this study. This study was supported by "The Survey of Korean Indigenous Species" supported by National Institute of Biological Resources (NIBR) of Ministry of Environment of Korea.

\section{REFERENCES}

Ashmead WH, 1900. Classification of the Ichneumon flies, or the superfamily Ichneumonoidea. Proceedings of the United States National Museum, 23:1-220.

Belshaw R, Quicke DLJ, 2002. Robustness of ancestral state estimates: evolution of life history strategy in ichneumonoid parasitoids. Systematic Biology, 51:450-477.

Brues CT, 1910. The parasitic Hymenoptera of the Tertiary of Florissant, Colorado. Bulletin of the Museum of Comparative Zoology, Harvard University, 54:1-125.

Ceballos G, 1925. Himenópteros de Español Familie Ichneumonidae. Memoria. Academia de Ciencias Exactas, Ficas y Naturales, Madrid, 31:1-293.

Enderlein G, 1912. Beiträge zur Kenntnis aussereuropäischer Ichneumoniden. II. Ophioninae. Der Gattung Thyreodon und ihre Verwandten. Zoologischer Anzeiger, 39:624-632.

Gaulle J, 1908. Catalogue systematique et biologique des Hyme-

Korean name: ${ }^{*}$ 거짓왕자루맵시벌 (신칭) 
noptes de France (Extrait de la Feuille des Juenes Naturalistes, ann. 1906, 1907, 1908). Paul Klincksieck, Paris, pp. 1172.

Gistel J, 1848. Naturgeschichte des Thierreichs fürhöhere Schulen bearbeitet. Hoffman'sche Verlags-Buchhandlung, Stuttgart, pp. 1-216.

Gravenhorst JLC, 1823. Hellwigia novum insectorum genus. Nova Acta Physico Medica Academiae. Caesareae Leopoldino-Carolinae Naturae Curiosorum, 11:315-322.

Hedwig K, 1949. Eine neue Campoplegide (Hym. Ichn.). Entomologische Zeitschrift, 59:54-56.

Kasparyan DR, 1981. A guide to the insects of the European part of the USSR. Hymenoptera, Ichneumonidae. 11 Ctenopelmatinae. 12 Phrudinae. 13 Tersilochinae. 14 Cremastinae. 15 Campopleginae. 16 Ophioninae. Opredeliteli Faune SSSR, 3:316-431 (in Russian).

Kirchner LA, 1867. Catalogus Hymenopterorum Europae. Vindobonae, Wien, pp. 1-285.

Latreille PA, 1802. Histoire naturelle, générale et particuliere, des Crustacés et des Insectes. Tome troisième. Paris, pp. 1468 (Ichneumonidae pp. 318-327).

Meyer NF, 1926. Tableaux pour determination des genres de la famille des Ichneumonides. Deuxieme partie. Sous-familles des Ophionines et des Tryphonines. Defense des Plantes, 3:199-217 (in Russian).

Quicke DLJ, Fitton MG, Broad GR, Crocker B, Laurenne NM, Miah MI, 2005. The parasitic wasp genera Skiapus, Hellwigia, Nonnus, Chriodes, and Klutiana (Hymenoptera, Ichneumonidae): recognition of the Nesomesochorinae stat. rev. and Nonninae stat. nov. and transfer of Skiapus and Hellwigia to the Ophioninae. Journal of Natural History, 39:25592578 .

Schmiedeknecht O, 1914. Die Schlupfwespen (Ichneumonidae) Mitteleuropas, insbesondere Deutschlands. In: Die Insekten
Mitteleuropas (Ed., Schoeder C). Franckh'sche Verlagshandlung, Stuttgart, pp. 113-170.

Szépligeti G, 1905a. Hymenoptera. Ichneumonidae (Gruppe Ophionoidea), subfam. Pharsaliinae-Porizontinae. Genera Insectorum, 34:1-68.

Szépligeti G, 1905b. Übersicht der paläarktischen Ichneumoniden. I. Theil. Annales Historico-Naturales Musei Nationalis Hungarici, 3:508-540.

Townes H, Momoi S, Townes M, 1965. A catalogue and reclassification of the eastern Palearctic Ichneumonidae. Memoirs of the American Entomological Institute, 5:1-661.

Townes HK, 1970. The genera of Ichneumonidae, Part 3. Memoirs of the American Entomological Institute, 13:1- 307.

Wahl DB, 1991. The status of Rhimphoctona, with special reference to the higher categories within Campopleginae and the relationships of the subfamily (Hymenoptera: Ichneumonidae). Transactions of the American Entomological Society, 117:193-213.

Wahl DB, 1999. Classification and systematics of the Ichneumonidae (Hymenoptera) [Internet]. Accessed 10 Feb 2011, <http://iris.biosci.ohio-state.edu/catalogs/ichneumonids/ campopleginae_genera.html>.

Yu DS, Horstmann K, 1997. A catalogue of world Ichneumonidae (Hymenoptera). Memoirs of the American Entomological Institute, 58:1-1558.

Yu DS, Van Achterberg C, Horstmann K, 2005. World Ichneumonoidea 2004. Taxonomy, biology, morphology and distribution [Ichneumonidae]. Taxapad 2005 (Scientific names for information management) interactive catalogue on CDROM. Taxapad, Vancouver. 